\title{
Controlling tuberculosis: we can't do it if we don't find the cases
}

\author{
D.A. Enarson ${ }^{1}$
}

SUMMARY The current international strategy for the control of tuberculosis emphasizes two different targets: a high success rate for the treatment of tuberculosis cases with an emphasis on positive sputum smear cases and a high case detection rate. Recent analyses indicate that while progress is being made towards successful treatment, targets for case-finding are not being achieved.

\section{Objectives: detection and control}

Organized public health programmes for the control of tuberculosis were made possible by the development of modern chemotherapy to treat the disease. Shortly after chemotherapy was shown to be able to permanently cure tuberculosis patients, a national conference was called in the United States of America to discuss how such a programme might be structured [1]. The conference stressed the importance of government responsibility for tuberculosis control, ambulatory chemotherapy for tuberculosis patients, standardization of treatment regimens, passive case detection, bacteriological monitoring and the use of bacille Calmette-Guérin (BCG) vaccination.

The World Health Organization (WHO) quickly followed this with an international initiative to define the basic principles of the National Tuberculosis Control Programme [2]. Tuberculosis control was the first focused programme of WHO.

After it defined the National Tuberculosis Control Programme, WHO moved quickly to model the tuberculosis epidemic and the impact of interventions [3]. This modelling exercise indicated that the ratelimiting step in tuberculosis control was case-finding, i.e. even if we treated cases very well, if we did not find a large proportion of the cases, we could not affect the prevalence of tuberculosis, the driving state of transmission. This observation led WHO to set case-finding targets and actively apply them to communities. Extensive activities were undertaken to reach these targets in those communities and we encountered some difficulties with the process. One community, for example, determined targets according to the model, promptly set out with a mobile X-ray van to find the requisite number of cases and, when the cases were recorded, returned to home base. At the start of the next case-finding period, the researchers promptly went out in the van to find the same cases all over again.

The fallacy of this simplistic approach was slowly realized even though evidence had been available since the introduction of chemotherapy in the 1950s. In the early publications of Crofton, the negative effect of poor treatment prior to the introduction of multidrug chemotherapy was evident with a rise in prevalence [4]. This was be-

${ }^{1}$ International Union Against Tuberculosis and Lung Disease, Paris, France.

المجلة الصحية لشرق المتوسط، منظمة الصحة العالمية، المجلد التاسع، العدد ؟، بم بـ 
cause lives were saved but the disease was not cured and because of an accompanying rise in clinically significant resistance to the medications [4]. The trend was confirmed in India during the same period [5]. These observations, however, were virtually ignored until the early 1970s when Grzybowski emphasized the point previously made by Crofton and by Frimodt-Møller that poor chemotherapy is worse than no chemotherapy because it increases prevalence by saving lives without curing the disease and because it promotes drug resistance [6]. This has been repeatedly demonstrated [7].

The negative effect of those strategies affected political commitment to tuberculosis services at a time when emphasis was shifting from focused interventions to building the capacity of primary services. The new emphasis was on the most peripheral level of public institutions and on mobilization of the community for the promotion of health as part of a broad development strategy. Interest in tuberculosis control in low-income countries waned steadily with the decline of tuberculosis in wealthier countries and the shift of emphasis of international organizations towards the target of 'Health for all by the year 2000'. By 1989, the tuberculosis section of WHO had been reduced to one individual working part-time.

By the end of the 1980s, interest in focused activities for tuberculosis control in low-income countries remained alive among international agencies virtually only in the International Union Against Tuberculosis and Lung Disease (UNION). When UNION was asked by the Ministry of Health of the United Republic of Tanzania to develop a plan for a National Tuberculosis Programme within the context of a combined programme addressing tuberculosis and leprosy, the emphasis was placed on quality of care for sputum smear-positive cases while retaining comprehensive case detection as a priority (National Tuberculosis Workshop, Arusha, Tanzania, February 24, 1977). From this exercise came the current targets for tuberculosis control of $85 \%$ of detected cases cured and $70 \%$ of existing cases detected.

\section{Monitoring case detection}

Setting the target for case-finding immediately highlighted an important monitoring problem that dominated discussions of international experts during the 1960s and 1970s. Various approaches had been used to monitor case detection, and routine reporting of cases at the international level had been inefficient and imprecise. Examining reports to WHO, Bulla concluded that the global number of TB cases had declined substantially in the previous decades [8]. Styblo and Rouillon challenged this and concluded that the routine statistics were unreliable [9]. They estimated 8 million new cases per year with 2 million deaths.

National prevalence surveys were widely applied by WHO in the 1950s and 1960s in attempts to determine the number of existing cases and to evaluate case-finding [10]. This approach was adopted and promoted in the Western Pacific Region where periodic surveys were undertaken in Japan, Korea, Taiwan and China [11]. The surveys identified cases and permitted an evaluation of comprehensiveness and quality of tuberculosis services in the communities in which they were carried out. Unfortunately, those performing the surveys did not pursue the full potential for analysis of the data produced by them, although others demonstrated the power of the information to provide an insight into comprehensiveness and quality [12]. In the end, the sur-

المجلة الصحية لشرق المتوسط، منظمة الصحة العالمية، المجلد التاسع، العدد ؟، ب..ب 
veys were criticized as too expensive and difficult to interpret.

The annual risk of tuberculosis infection was subsequently developed as a comprehensive approach to monitoring casefinding [13-15]. This was further extended to estimate the number of existing cases in a community and proposed as a means to monitor case-finding [16,17]. This approach, however, was flawed by circular arguments [18].

While it is clear that there are a variety of sources of information that can be used to estimate the number of existing cases and monitor case-finding, each of these sources has limitations. Estimating cases and monitoring case-finding (and monitoring progress towards the global target for case-finding) is fraught with difficulties. In the face of these difficulties, Dye et al. have started an interactive process to develop reasonable estimates of case numbers for each country, using all existing information [19]. This approach is creative, interactive and flexible and may provide the best estimates possible. The flexible approach has allowed estimates to be sensibly revised [20].

\section{Identifying missing cases}

These advances notwithstanding, we need a rational approach for responding to the issue of finding the missing patients. In the 2003 WHO report, of 266606 estimated new smear-positive cases in 2001, 68924 (25.9\%) were notified in regular reports to the WHO Regional Office for the Eastern Mediterranean. Clearly this is far from the Region's target of $70 \%$.

This figure, however, includes a number of different variables (Table 1). The first is non-reporting. Of the 23 countries in the Region, 4 did not report to WHO for the year 2001. An additional 3 countries are in the expansion phase of tuberculosis services. Another 3 countries have portions of their population living in areas that are inaccessible because of political instability. In those countries with stable political and social conditions where the tuberculosis services are expanded throughout the country, 3 countries have private sectors providing a substantial proportion of health services. This leaves 10 countries where a high proportion of tuberculosis services are provided or closely supervised by the public health services. Among these 10 countries, the estimated number of cases is quite likely to be substantially overestimated in 3 .

Among the 7 remaining countries, the case detection rate was $78.7 \%$ of estimated cases reported in the year 2001. Among the $21.3 \%$ of missing cases, some may have been detected and treated either in other sectors of the health services or within the public sector but not reported (many countries have less than $100 \%$ reporting by basic management units).

A reasonable estimate of what was reported is $78.7 \%$. This takes into account patients treated in non-reporting sectors and those from reporting sectors whose reports were not submitted, as well as those who were truly undetected. Moreover, we might assume that in countries where there might be an overestimation of existing cases, the true number of cases is $50 \%$ of the estimated figure. Using these 2 assumptions, we can calculate the number and proportion of missing cases, or cases that might reasonably be found during the routine operation of a health service such as those of the 7 countries identified above (Table 1). On the basis of this estimation, the case detection rate for the Region would be $34.3 \%$ rather than $21.3 \%$. Moreover, if countries that are in the early stages

المجلة الصحية لشرق المتوسط، منظمة الصحة العالمية، المجلد التاسع، العدد ؟، ب... 


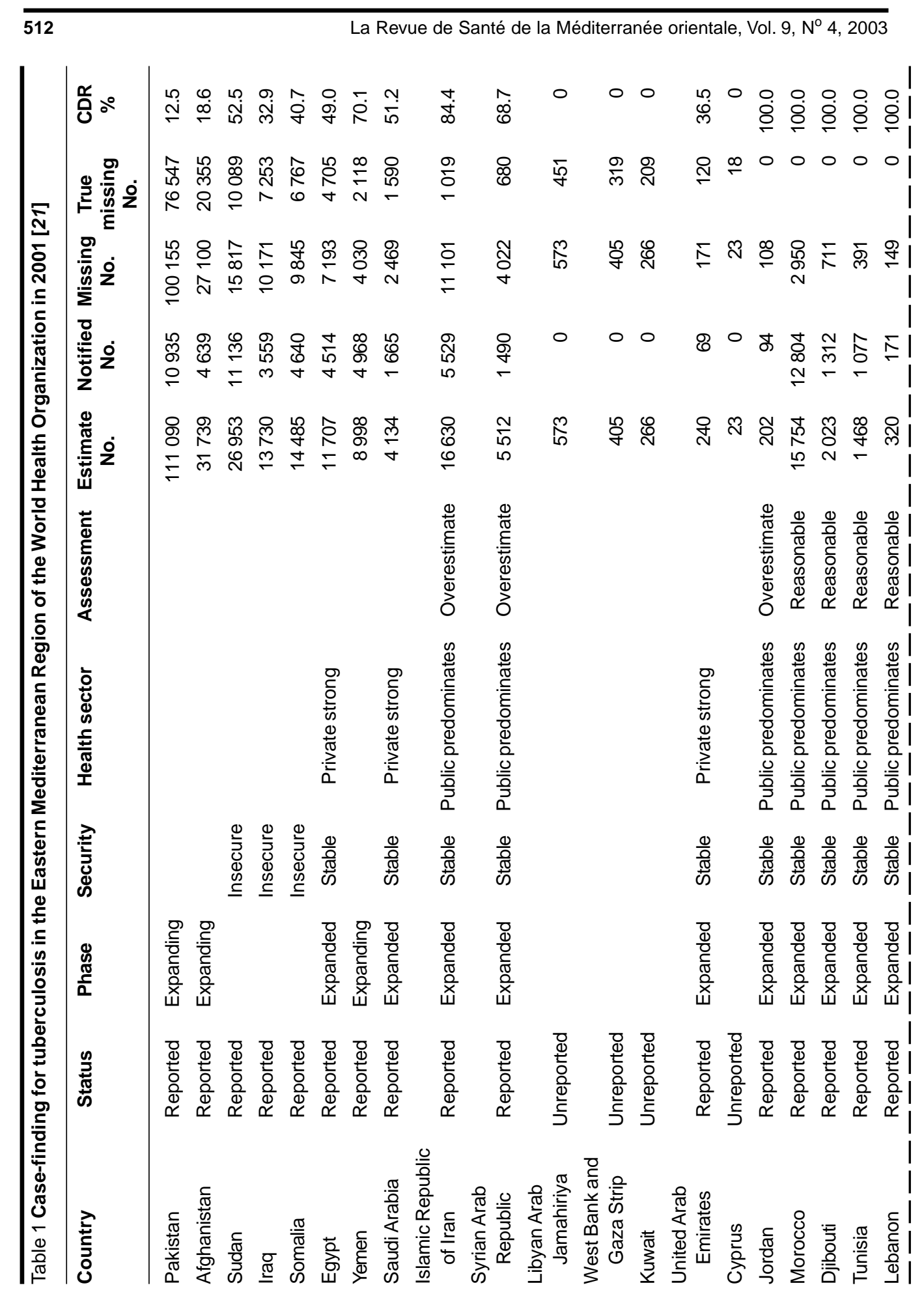

المجلة الصحية لشرق المتوسط، منظمة الصحة العالمية، المجلد التاسع، العدد ع، ب... 
of expansion or that did not report cases in 2001 were excluded the case detection rate would be $60.0 \%$.

\section{Confirming the location of missing cases}

Clearly the greatest number of missing cases (99 020 cases, $74.9 \%$ of 'true missing' cases) is in countries still expanding tuberculosis services. The expansion of high quality public sector tuberculosis services in these 3 countries must remain the highest priority for case-finding for the Region.

A very small proportion of such cases (997, $0.8 \%$ ) would be expected to be in countries that did not report cases in 2001. Efforts must be made to obtain these reports routinely.

Table 2 demonstrates the distribution of missing cases in the remaining countries. More than $95 \%$ of the cases that could be found in a routine programme might be expected to be in just 5 countries: Sudan, Iraq, Somalia, Egypt and Saudi Arabia.

Approximately one-quarter of missing cases in this group of countries might not exist as they may be phantoms, due to overestimation. The arbitrary adjustment for this overestimation indicates that almost three-quarters of the cases that might reasonably be found under routine programme conditions are in countries with political instability and a further one-fifth are in countries where the private sector provides a substantial proportion of health services.

These calculations are hypothetical, based on certain assumptions that may or may not be valid. How can these hypotheses be tested? What can we do to determine whether the cases are likely to be sequestered in the areas we have identified in this calculation?

المجلة الصحية لشرق المتوسط، منظمة الصحة العالمية، المجلد التاسع، العدد ع، ب... 


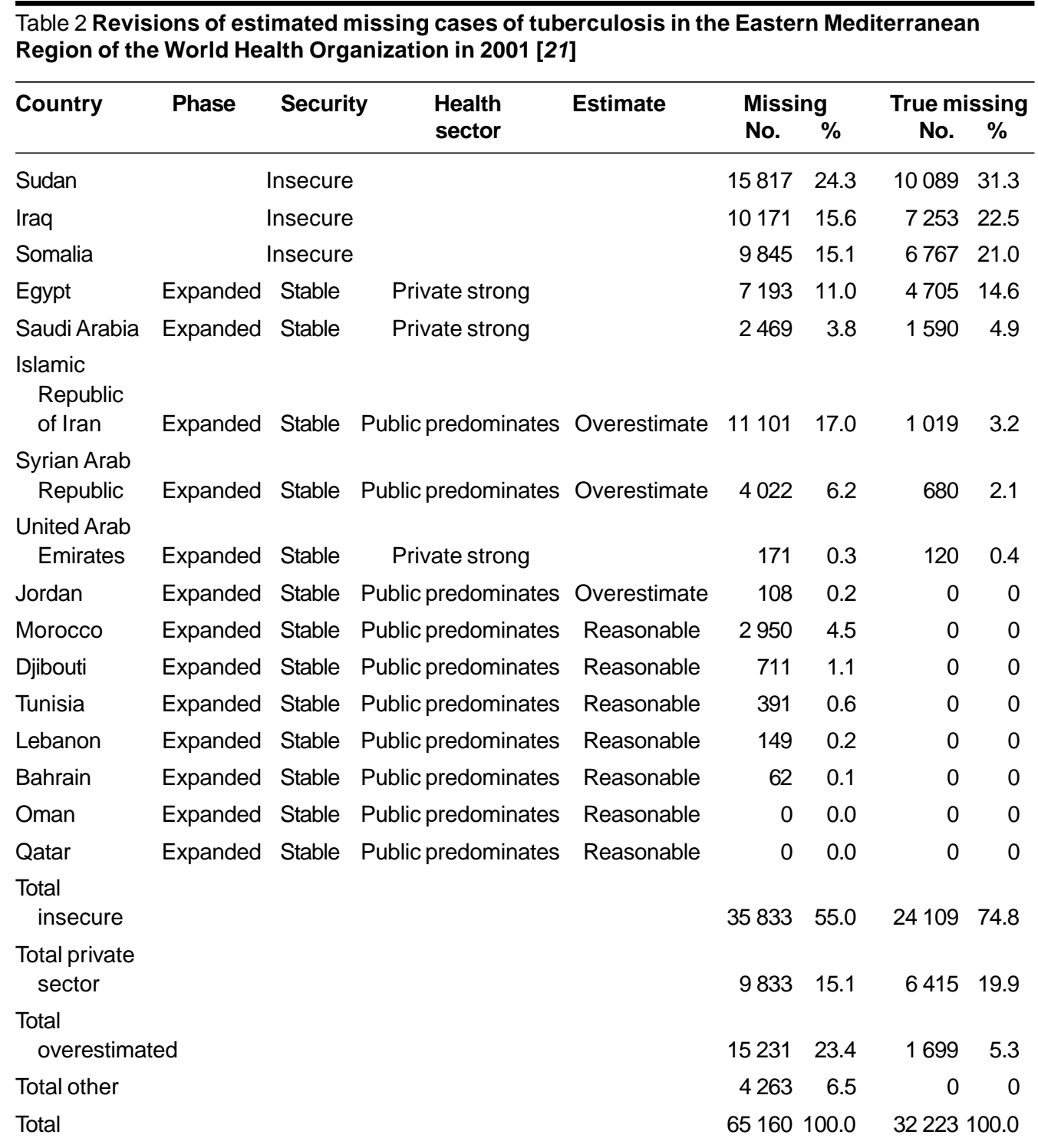

Excluding expanding and unreported countries.

A first step is to select those countries, e.g. the Islamic Republic of Iran, the Syrian Arab Republic and Jordan, where the expected number of cases is likely to be overestimated and to review their data. This has been done for both the Islamic Republic of
Iran and the Syrian Arab Republic with subsequent adjustments in the estimates.

A second step is to obtain reports from countries not currently reporting. In addition, it is important to determine the comprehensiveness of reporting for each

المجلة الصحية لشرق المتوسط، منظمة الصحة العالمية، المجلد التاسع، العدد ع، ب ب. 
country with a substantial proportion of missing cases. This can be done quite easily by identifying every reporting unit in a country and determining in the previous 4 quarters what proportion of units submitted reports. This should be routinely associated with all reporting of programme activities. Moreover, where a programme has been in place for more than 6 quarters, it is possible to estimate the number of unreported cases by averaging the number of previously reported cases from the unit and assigning this average as the number of cases likely to have been diagnosed within that unit.

In an effort to determine the probable number of cases not reported or not detected due to political instability, several steps must be taken. First, agreement needs to be reached concerning the population likely to be living in the unstable areas. This should not include those who have been displaced to other locations either inside or outside the country. Second, once the population has been agreed upon, a probable case rate should be established. This can be determined from the rates in corresponding stable populations near the area of political instability or from information available from periods when there was no political instability. These rates can then be applied to the population. This number of cases is likely to be an underestimate of the true cases as political instability is often associated with an increase in disease burden [21].

Many development partners stress the role of the private sector and a need to invest large amounts of energy and resources in engaging them in providing tuberculosis services. This may or may not be appropriate. It is quite possible that the private sector plays a large role in providing services in some locations within the Region where case detection is low. We have estimated that this might be an important factor in low case detection in 3 countries. Two of those countries, Egypt and Saudi Arabia, contribute a substantial number of the undetected cases in the Region. As part of the initiative on operations research in the Region in a collaboration between WHO, UNION and the Special Programme for Research and Training in Tropical Diseases, simple surveys have proven to be effective in identifying the role of the private sector in tuberculosis services. These simple surveys would be ideal as starting points in assessing this role.

Finally, there are undoubtedly undetected cases that do not access health services at all. Although quantifying this is a challenge, the national tuberculosis prevalence survey is one means to do so. These surveys are complex and expensive and sometimes not possible. One way to document the possibility of limited access to services at certain locations within a country is to identify basic management units that provide high quality services, and among them, those that have done so consistently over a prolonged period (for example, more than 3 years). From these centres, it is possible to determine the maximum and median numbers of cases reported over time and to calculate case notification rates. These calculations can then be applied to other basic management units to identify individual units that report deficient numbers of cases. Investigators can then explore the validity of these calculations and the reasons for discrepancies.

Another possible approach is a prevalence survey of health service use, focusing on those who, by policy, should have sought care and should have had sputum smear examinations as suspect cases of tuberculosis. Prevalence surveys of tuberculosis are challenging and complex because the disease is rare. Suggestive symptoms,

المجلة الصحية لشرق المتوسط، منظمة الصحة العالمية، المجلد التاسع، العدد ع، ب...T 
however, are not rare. It is the care-seeking behaviour of these suspects that is important in evaluating behaviour in terms of accessing health services. Such surveys are neither difficult nor costly and can be performed locally.

\section{Conclusion}

A great deal of attention is being given to case-finding in tuberculosis services, because programmes are not yet attaining tar- gets for case-finding in the overall strategy of tuberculosis control. Clearly, if we do not find and treat a substantial proportion of existing cases, the strategy of tuberculosis control will fail. It is important to look behind the figures to understand the reasons why progress is lagging. It is quite possible to undertake critical evaluation of this question using relatively simple and straightforward means that can be carried out within the programmes themselves.

\section{References}

1. National Tuberculosis Association. Recommendations of the Arden House Conference on Tuberculosis. American review of respiratory disease, 1960, 81: 482-4.

2. Expert Committee on Tuberculosis, 8th Report. Geneva, World Health Organization, 1964 (WHO Technical Report Series, No. 290).

3. Waaler H, Geser A, Andersen S. The use of mathematical models in the study of the epidemiology of tuberculosis. American journal of public health, 1962, 6: 1002-13.

4. Crofton J. The contribution of treatment to the prevention of tuberculosis. Bulletin of the International Union against Tuberculosis, 1962, 32:643-53.

5. Frimodt-Møller J. Changes in tuberculosis prevalence in a south Indian rural community following a tuberculosis control programme over a 7-years period. Indian journal of tuberculosis, 1962, 9:187-91.

6. Grzybowski S, Enarson DA. The fate of cases of pulmonary tuberculosis under various treatment programmes. Bulletin of the International Union against Tuberculosis, 1978, 53:70-5.

7. Grzybowski S. Drugs are not enough; failure of short-course chemotherapy in a district in India. Tubercle and lung diseases, 1993, 74:145-6.

8. Bulla A. World Health Statistics Report. Tuberculosis patients-how many now? Chronicle of the World Health Organization, 1977, 31:35-40.

9. Styblo K, Rouillon A. Estimations concernant l'incidence mondiale de la tuberculose pulmonaire positive a l'examen des frottis d'expectoration. Non fiabilite des chiffres officiels rapportes de tuberculose. [Estimations concerning the world incidence of positive pulmonary tuberculosis from sputum smears. Unreliability of official totals reported on tuberculosis.] Bulletin of the International Union against Tuberculosis, 1981, 56(3-4):129-38.

10. International work in tuberculosis, 1949-1964. Geneva, World Health Organization, 1965.

11. Shimao T. Measuring tuberculosis: the role of the Tuberculosis Prevalence Sur-

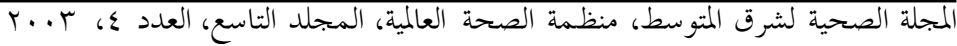


vey as developed in Eastern countries. Tubercle and lung diseases, 1993, 5: 293-4.

12. Schulzer M et al. An analysis of pulmonary tuberculosis data from Taiwan and Korea. International journal of epidemiology, 1987, 16:584-9.

13. Styblo K, Meijer J, Sutherland I. The transmission of tubercle bacilli. Its trend in a human population. Bulletin of the International Union against Tuberculosis, 1969, 42:5-104.

14. Styblo K, Meijer J, Sutherland I. La transmission du bacille tuberculeux: son evolution au sein d'une collectivite humaine. [The transmission of tubercle bacilli: its trend in a human population.] Bulletin of the World Health Organization, 1969, 41:137-78.

15. Sutherland I. Recent studies in the epidemiology of tuberculosis, based on the risk of being infected with tubercle bacilli. Advances in tuberculosis research, 1976, 19:1-63.

16. Styblo $\mathrm{K}$. The relationship between the risk of tuberculous infection and the risk of developing infectious tuberculosis.
Bulletin of the International Union against Tuberculosis, 1985, 60:117-9.

17. Murray CJL, Styblo K, Rouillon A. Tuberculosis in developing countries: burden, intervention and cost. Bulletin of the International Union against Tuberculosis, 1990, 65:2-20.

18. Rieder HL. Methodological issues in the estimation of the tuberculosis problem from tuberculin surveys. Tubercle and lung diseases, 1995, 76:114-21.

19. Dye $\mathrm{C}$ et al. Global burden of tuberculosis. Estimated incidence, prevalence, and mortality by country. Journal of the American Medical Association, 1991, 282:677-86.

20. Global tuberculosis control. Surveillance, planning, financing. Geneva, World Health Organization, 2003 (WHO Report, No. WHO/CDS/TB/2003.316 amended).

21. Barr RG, Menzies R. The effect of war on tuberculosis: results of a tuberculin survey among displaced persons in El Salvador and a review of the literature. Tubercle and lung diseases, 1994, 75: 251-9.

المجلة الصحية لشرق المتوسط، منظمة الصحة العالمية، المجلد التاسع، العدد ع، ب... 